\title{
Case report of unicornuate uterus with subfertility
}

\author{
Jahnavi Esanakula ${ }^{1 *}$, Maheshwari Mohan Kumar ${ }^{1}$, Asha S. Vijay ${ }^{1}$, Rajsri Thuthikadu \\ Rajasekaran $^{2}$
}

\begin{abstract}
${ }^{1}$ Department of Reproductive Medicine, Garbhagudi IVF Hospitals, Bangalore, Karnataka, India
${ }^{2}$ Department of Community Medicine, Evidencian Research Association, Bangalore, Karnataka, India
\end{abstract}

Received: 08 January 2021

Revised: 30 March 2021

Accepted: 31 March 2021

\section{*Correspondence: \\ Dr. Jahnavi Esanakula, \\ E-mail: jahnavie3001@gmail.com}

Copyright: (C) the author(s), publisher and licensee Medip Academy. This is an open-access article distributed under the terms of the Creative Commons Attribution Non-Commercial License, which permits unrestricted non-commercial use, distribution, and reproduction in any medium, provided the original work is properly cited.

\begin{abstract}
Most often the uterine developmental anomalies are missed until later in life presenting as infertility. This case report is of a couple presented with primary infertility of six years. 3D ultrasonography helps in for clinical suspicion of a uterine anomaly. The wife had a left unicornuate uterus with adequate uterine cavity and right rudimentary horn and also poor ovarian reserve. The husband had astheno-teratozoospermia. After a failed IVF frozen embryo transfer the couple were advised and underwent IVF-ICSI of donor oocytes with husband sperm. One 5AB blastocyst transferred and at 5 weeks and 6 weeks scans gestational sac along with yolk sac and foetal heart pulsations were noted, respectively. Single embryo transfer with good quality blastocyst is preferable for a unicornuate uterus since there is a risk of pre term labour.
\end{abstract}

Keywords: Unicornuate uterus, Astheno-teratozoospermia, IVF, ICSI, Oocytes donor

\section{INTRODUCTION}

A unicornuate uterus is a form of congenital uterine anomalies resulting from fusion defects of mullerian ducts during development. Depending on the severity of the defect, mullerian anomalies range from mullerian agenesis to arcuate uterus. Uterine anomalies prevalence ranges from the $1-10 \%$ in general population and they range from $2-8 \%$ in subfertile population. ${ }^{1}$ In women with miscarriages, it is $5-30 \% .^{1}$ The true prevalence of uterine anomalies is difficult to determine, as the general population is not often screened for them. In addition, no universally accepted classification for uterine anomalies makes it difficult to identify the prevalence of each anomaly exclusively.

Unicornuate uterus accounts for about $13 \%$ of all anomalies of mullerian duct. ${ }^{2}$ A unicornuate uterus is associated with urinary tract abnormalities and gynaecological complications such as endometriosis, infertility, urinary tract anomalies and hematometra. ${ }^{3,4}$ Obstetric complications like abnormal presentations, miscarriages, ectopic pregnancies and preterm deliveries are also seen and attributed to abnormal uterine blood flow, incompetence of cervix and decreased muscle mass the uterus., ${ }^{5,6}$ Hystero-laproscopy is very useful for acurate diagnosis of unicornuate uterus and in the assessment of rudimentary horn. ${ }^{7} 84 \%$ of unicornuate uterus patients had rudimentary horn. ${ }^{8}$ Complications with rudimentary horn are ectopic pregnancy, torsion, endometriosis and chronic pelvic pain.

We are reporting a case of unicornuate uterus with poor ovarian reserve presented to the fertility clinic.

\section{CASE REPORT}

A couple, 30 years old wife and 35 years old husband came to the clinic with primary infertility of 6 years 
duration. The wife had irregular cycles with bleeding for 5-6 days every 1.5-2 months since menarche with the spasmodic type of dysmenorrhoea. She had no history of medical illness or any previous surgeries. The husband was a known case of bronchial asthma and was using budecort inhalation as and when needed. BMI of wife and husband were 24.7 and $32 \mathrm{~kg} / \mathrm{m}^{2}$ respectively. Before coming to the clinic, the couple underwent two cycles of ovulation induction and timed intercourse, two cycles of ovulation induction and IUI and one cycle of IVF. During the IVF cycle, the antagonist protocol was used and six oocytes were retrieved. ICSI was done and one compacting grade 1 and two ten cell grade 1 embryo were transferred in the next cycle but the patient did not conceive.

The couple were investigated with 3D ultrasound, which showed left unicornuate uterus with adequate uterine cavity and antral follicular count of 3. On hysterolaparoscopy, well developed left unicornuate horn was seen. Right side rudimentary right horn with no cavity noted along with rudimentary tube-like structure and flimsy adhesions between ovary and tube. A single endometrial polyp was noted and polypectomy done. Her FSH, LH, prolactin and AMH were $6.2 \mathrm{mIU} / \mathrm{ml}, 2.14$ $\mathrm{mIU} / \mathrm{ml}, 11.34 \mathrm{ng} / \mathrm{ml}$ and $0.69 \mathrm{ng} / \mathrm{ml}$ respectively. Semen analysis of the husband showed astheno-teratozoospermia with a count of $17 \mathrm{M} / \mathrm{ml}$, progressive motility of $28 \%$ and $2 \%$ morphologically normal sperms. Sperm DNA fragmentation using SCSD was $22 \%$.

IVF was advised in view of poor ovarian reserve. Short agonist protocol was used and three oocytes were retrieved. ICSI was done on day four 1-12 celled grade1, and 1-8 celled grade 1 embryos were frozen. The embryos were transferred in a subsequent cycle after endometrial preparation and the patient did not conceive. The couple were counselled for another IVF cycle and explained about the need for pooling of embryos. They were given the option of a donor oocyte. The couple chooses to go for donor oocyte and ICSI with husband sperm. Among the resulting embryos, one $5 \mathrm{AB}$ blastocyst transferred after preparing the recipients endometrium. The beta hCG was $1958 \mathrm{mIU} / \mathrm{L}$ after 14 days of embryo transfer. At 5 weeks and 6 weeks scans, gestational sac along with yolk sac and foetal heart pulsations were noted respectively.

\section{DISCUSSION}

Unicornuate uterus is one of the uterine anomalies which presents with obstetric complications. ${ }^{5,6}$ However in the present scenario the primary complaint which brought the patient to hospital for analysis is primary subfertility. Other inherent factors of the couple like decreased ovarian reserve and male factors might have also contributed to the subfertility in the couple. Many urinary tract anomalies were associated with uterine anomalies, but no urinary tract anomaly was found in the present subject. $^{3}$ Hystero-laproscopy was proposed as ideal investigation for diagnosis of uterine anomalies but in the advent of introduction of 3D scan, it can be used successfully to diagnose the uterine anomaly and also asses the rudimentary horn. ${ }^{7}$ Elective single embryo transfer has been shown to reduce the incidence of multiple pregnancies especially in young women at the cost of slight decrease in live birth rates. It was more used in women with uterine factors to reduce the complications associated with multiple pregnancies. ${ }^{9}$ This single embryo transfer was successfully used in the present subject and a single live pregnancy achieved.

\section{CONCLUSION}

Patients with unicornuate uterus have increased gynaecological problems. Infertility or recurrent pregnancy loss can be the presenting feature of such disorders. Hence, patients with clinical suspicion have to be screened with thorough $3 \mathrm{D}$ ultrasonography as a $2 \mathrm{D}$ ultrasonography can miss such a diagnosis especially in inexperienced hands. Single embryo transfer with good quality blastocyst is preferable for a unicornuate uterus since there is a risk of preterm labour.

\section{ACKNOWLEDGMENTS}

We acknowledge the technical support literature search and manuscript editing by Evidencian research associates.

\section{Funding: No funding sources \\ Conflict of interest: None declared \\ Ethical approval: Not required}

\section{REFERENCES}

1. Chan YY, Jayaprakasan K, Tan A, Thornton JG, Coomarasamy A, Raine-Fenning NJ. Reproductive outcomes in women with congenital uterine anomalies: a systematic review. Ultrasound Obstet Gynecol. 2011;38(4):371-82.

2. Forstner R, Hricak H. Congenital malformations of uterus and vagina. Radiologe. 1994;34(7):397-404

3. Fedele L, Bianchi S, Agnoli B, Tozzi L, Vignali M. Urinary tract anomalies associated with unicornuate uterus. J Urolog. 1996;155(3):847-8.

4. Reichman D, Laufer MR, Robinson BK. Pregnancy outcomes in unicornuate uteri: a review. Fertil Steril. 2009;90(5):1886-94

5. Akar ME, Bayar D, Yildiz S, Ozel M, Yilmaz Z. Reproductive outcome of women with unicornuate uterus. Austral New Zeal J Obstetr Gynaecol. 2005;45:148-50.

6. Chan YY, Jayaprakasan K, Tan A, Thornton JG, Coomarasamy A, Raine-Fenning NJ. Reproductive outcomes in women with congenital uterine anomalies: a systematic review. Ultrasound Obstet Gynecol. 2011;38:371-82.

7. Motashaw ND, Dastur A, Vaidya RA, Aloorkar M. Laparascopy for resolving Mullerian abnormalities. J Reprod Med. 1978;21(1):20. 
8. Heinonen P. Unicornuate uterus and rudimentary horn. Fert Ster. 1997;68(2):224-30.

9. Luke B, Brown MB, Grainger DA, Cedars M, Klein N, Stern JE. Practice patterns and outcomes with the use of single embryo transfer in the United States. Fertil Steril. 2010;93(2):490-8.
Cite this article as: Esanakula J, Kumar MMK, Vijay AS, Rajasekaran RT. Case report of unicornuate uterus with subfertility. Int J Reprod Contracept Obstet Gynecol 2021;10:2072-4. 